\title{
Mobil Uygulamaların Performanslarının Veri Zarflama Analizi ile Değerlendirilmesi
}

\author{
Performance Evaluation of Mobile Applications with Data Envelopment Analysis
}

\author{
Aliye Ayça SUPÇíLLER*1,a, Muhammet Enis BULAK ${ }^{2, b}$ \\ ${ }^{1}$ PamukkaleÜniversitesi, Mühendislik Fakültesi, Endüstri Mühendisliği Bölümü, 20160, Denizli

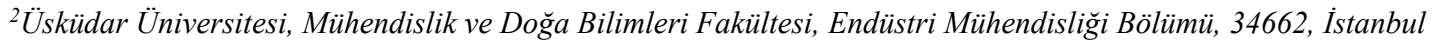

• Geliş tarihi / Received: 18.09.2019 • Düzeltilerek geliş tarihi / Received in revised form: 07.04.2020 • Kabul tarihi / Accepted: 02.06.2020

$\ddot{O} z$

Performans değerlendirmesi işletmelerin operasyonlarını etkin ve verimli bir şekilde sürdürebilmeleri için önemli bir kavramdır. Özellikle çok sayıda girdi ve çıtının bulunması halinde karar verme birimlerinin etkinliklerinin ölçülmesinde kullanılan yöntemlerden biri veri zarflama analizidir (VZA). Bu çalışmada, VZA yöntemi ile mobil kullanıcılar tarafından sıkça kullanılan uygulamaların verimlilik ve etkinlik analizi gerçekleştirilmiştir. Öncelikle, VZA için mobil uygulamalarda girdi ve çıktı olabilecek ortak değişkenler tespit edilmiş ve değişkenlerin tanımlamaları yapılarak ölçüm modeli geliştirilmiştir. Geliştirilen bu model doğrultusunda çıktı odaklı CCR yaklaşımı ile uygulamaların göreceli etkinlik puanları hesaplanmıştır. Sonuçlar doğrultusunda etkin olmayan mobil uygulamalar analiz edilerek gerekli iyileştirmeler sunulmuştur.

Anahtar kelimeler: Mobil Uygulamalar, Performans Ölçümü, Verimlilik, Veri Zarflama Analizi

\begin{abstract}
Performance evaluation is an important concept for companies to sustain their operations effectively and efficiently. Data envelopment analysis is one of the methods used to measure the effectiveness of decision-making units, especially if there are many inputs and outputs. In this study, efficiency analysis of the mobile applications is performed with data envelopment analysis (DEA). Firstly, common variables that can be input and output for DEA in mobile applications have been identified and the measurement model has been developed by defining the variables. Based on this model, the relative efficiency scores of the applications were calculated with the output oriented CCR approach. According to the results, inefficient mobile applications were analyzed, and necessary improvements are presented.
\end{abstract}

Keywords: Mobile Applications, Performance Measurement, Efficiency, Data Envelopment Analysis

\footnotetext{
*a Aliye Ayça SUPÇiLLER; asupciller@pau.edu.tr; Tel: (0258) 29631 36; orcid.org/0000-0001-5234-8234

${ }^{\mathrm{b}}$ orcid.org/0000-0003-3784-7830
} 


\section{Giriş}

Ak1ll telefonlar ve tabletler gibi mobil cihazlar günlük yaşamın birçok alanında sıkça kullanılmaya başlanmıştır. Bu doğrultuda, küresel mobil kullanıcilarının yarısından fazlasında internete erişmek için mobil cihazlar birincil yöntem haline gelmiştir. Diğer taraftan akıllı telefonların kullanımının hizla artan bir oranda benimsenmesi mobil uygulamaların sayısını, popülaritesini ve kullanımını çarpıcı biçimde arttırmaktadır (Guo vd., 2019). Mobil uygulamalar akıllı telefon, tablet, dizüstü bilgisayar ve mobil cihazlarda çalışması amaçlanan ve içeriksel bilgi girdisini almak için kullanılan yazılım uygulamalarıdır (Kaur ve Kaur, 2019). Mobil uygulamalar, çeşitli iş alanlarının ortak bir özelliği olarak karşımıza çıkmaktadır. Oyunlar gibi boş zamanı eğlenceli geçirmeyi sağlayan basit uygulamalardan, güvenlik açısından kritik etki alanındaki tıbbi uygulamalara kadar çeşitlilik göstermektedir. Jabangwe vd.'ne (2018) göre, mobil uygulama piyasası oldukça rekabetçi bir seviyede olup trilyon dolar değerindeki mobil cihaz pazarına önemli katkılar sağlamaktadır.

Amerika Birleşik Devletleri'nde, Android ve iPhone kullanıcıları, mobil uygulamaları kullanarak ayda yaklaşık 30 saat harcamakta ve ortalama olarak ayda 26.8 uygulama kullanmaktadır (Hwang vd., 2019). Mobil uygulamaların popülerliği hızla artmaya devam ederken, bireysel bir uygulamanın potansiyelini değerlendirmek zorlaşmaktadır. Pazar araştırmaları, uygulamaları indirme kararlarında, genel derecelendirme ve kullanıc incelemelerinin kilit faktörler olduğunu göstermiştir (Sigg vd., 2019). Ancak tek bir değişken veya ölçü ile performanslarını ölçmek mümkün değildir. Sadece birkaç oran, uygulamaların durumlarını yansıtsa da genel performansı ölçmek için yetersiz kalabilmektedir. $\mathrm{Bu}$ nedenle, uygulamanın tüm performansını yansıttığ 1 girdi ve çıktı kümelerini ağırlıklandırmak suretiyle birleştirmek gereklidir.

Sistem performanslarını ölçmekte faydalanılan metotlardan birisi etkinlik analizidir. Etkinlik analizi ile mal ya da hizmet üretimindeki girdilerin yani kaynakların ne derece etkin ve verimli kullanıldığı analiz edilmektedir. Parametrik olmayan etkinlik analiz yöntemi olarak en çok kullanılan yöntem ise Veri Zarflama Analizi (VZA)'dir (Bakırc1, 2006). VZA yönteminde, modellerin kullanımıyla, sistemlerin "toplam etkinlik", "teknik etkinlik" ve "ölçek etkinlik" gibi göstergeleri hesaplanabilmektedir (Özden, 2008).

$\mathrm{Bu}$ çalışma mobil uygulamaların etkinliğini VZA yöntemiyle analiz etmeyi amaçlamaktadır. Çalışmanın devamında literatür araştırması, üçüncü bölümünde VZA ile ilgili genel bilgi verilmiştir. Dördüncü bölümde mobil uygulamaların etkinliğinin ölçülmesinde kullanılan performans kriterleri, girdi ve çıktı değişkenleri belirlenmiştir. Tanımlanan bu girdi ve çıktı değişkenleriyle mobil uygulamaların etkinliğini ölçen model geliştirilmiş ve bu model ile 21 farklı uygulamanın göreceli etkinlik analizi gerçekleştirilmiştir. Beşinci bölümde analiz ve bulgular sunulmuştur. Ayrica, etkin olmayan uygulamaların etkin olabilmeleri için ulaşmaları gereken hedef değerler belirlenmiştir. Son bölümde ise sonuçlar ile ilgili yorumlar aktarılmış, tavsiye ve ileriye dönük yapılacak araştırmalar hakkında değerlendirmeler verilmiştir.

\section{Literatür}

VZA, hizmet sektörü için de oldukça kullanılan bir araçtır. Xing vd. (2013) tarafindan hizmet sektörü hakkında yapılan literatür taraması çalışmasında, VZA'nın taşıma, sağlık, perakende ve finans sektöründe performans geliştirme için kullanılan başlıca Yöneylem Araştırması tekniklerinden olduğunu belirtilmiştir. Petersen (2011), yazılım verimliliğini ölçme ve tahmin etme için yaptığı literatür taramasında, VZA'nın yazılım projelerinin etkinliğini ölçmek ve çok değişkenli analize olanak sağlamak için kullanılan güçlü bir yöntem olduğunu vurgulamıştır. Storto (2013) çalışmasında bilgisayar ekipmanı, müzik CD'si, CD, DVD ve kitap gibi ürünlerini çevrimiçi satan 52 web sitesini karşılaştırmak için VZA yöntemini uygulamıştır.

Ancak mobil uygulama alanında VZA ile yapılan çalışmalar çok azdır. Chatzigeorgiou ve Stiakakis (2011) kütüphane ve uygulama yazılımlarını VZA yöntemiyle karşılaştırmıştır. Önerilen yaklaşım 22 açık kaynaklı uygulamaya ve 22 açık kaynaklı kütüphaneye uygulanmıştır. VZA sonuçları, analiz edilen tasarımları genel verimliliklerine göre sinıflandırmaya ve hangi yönlerin iyileştirilebileceği ile ne ölçüde geliştirilebileceğini belirlemeye olanak tanımıştır. Her ne kadar yaklaşım küçük bir ölçüm kümesiyle sınırlı olsa da nesneye yönelik tasarımları karşılaştırmak için VZA yönteminin kullanılabilir olduğu görülmüştür. 


\section{Veri Zarflama Analizi}

VZA, çoklu girdi ve çıtılara sahip karar birimlerinin verimliliğini değerlendirmek için dinamik kolektif karşılaştırmalı sonuçlar sağlayan doğrusal bir programlama tekniğidir. VZA tekniği ilk olarak 1978 'de Charnes vd. tarafindan Farrell'in 1957'de yapmış olduğu üretken verimliliğin ölçülmesine dayanan seminer çalışması üzerine kurulmuştur (Farrell, 1957; Charnes vd., 1978, 1994). 1978'den günümüze, VZA ile ilgili hem teorik hem de uygulamada etkileyici gelişmeler yaşanmıştır (Cook ve Seiford, 2009). Bu nedenle de VZA hakkında farklı amaçlar için hazırlanan literatür çalışmaları mevcuttur (Liu vd., 2016). VZA, birçok araştırmacının dikkatini çeken, karar verme birimlerinin (KVB) göreceli verimliliğini ölçen ve avantajlarından dolayı geleneksel yöntemlerle karşılaştırıldığında sıkça kullanılan bir yöntemdir.

VZA'da, yapılacak olan çalışmanın amacına ve kapsamına göre değişkenlik gösteren birçok spesifik model seçeneği bulunmaktadır (Cook ve Seiford, 2009). Bunlardan en çok kullanılanları ve geleneksel olan yöntemlerden ikisi CCR ve BCC modelleridir. Eğer KVB'lerin toplam etkinliklerine ulaşılmak isteniyorsa ve ölçeğe göre sabit getiri sonucu üreteceği varsayımı bulunuyorsa CCR veya yönelimsiz modeller kullanılmaktadır. Diğer taraftan KVB'lerin teknik etkinlikleri değerlendirilmek isteniyorsa ve ölçeğe göre değişken getiri sonucu üreteceği varsayımı bulunuyorsa BCC modelinin kullanılması tercih edilmektedir (Özden, 2008). VZA modelinin doğru olarak tanımlanması KVB'lerin etkinliklerinin değerlendirilmesinde büyük önem taşımaktadır.

VZA'nın en temel modellerinden biri, 1978'de Charnes, Cooper and Rhodes tarafindan önerilen CCR modelidir (Cooper vd., 2007). CCR modelinde amaç, KVB'ler için, çıktı değerlerini girdi değerlerine göre maksimize etmektir ve ölçeğe göre sabit getiri esasına göre değerlendirme yapar. Literatürde sıkça kullanılan modellerden biri olan CCR modeli birden fazla girdi ve çıktıyı tek bir sonuç altında toplayabilen bir yapıya sahiptir. Spesifik olarak belirlenen KVB için çoklu fonksiyon yapısıyla beraber bir etkinlik sonucu üretmektedir. $\mathrm{Bu}$ modele göre, girdide yapılan bir birimlik değişim çıtıda bir birimlik değişime neden olmaktadır (Charnes vd., 1978).

Bir diğer temel model, ölçeğe göre değişken getiri esasına göre değerlendirme yapan ve Banker,
Charnes ve Cooper tarafindan önerilen BCC modelidir. BCC modeli daha esnek bir model olup ölçeğe göre değişken sonuçlar oluşturmaktadır (Banker vd., 1984). Bu model CCR modeline konvekslik kısitının eklenmesi ile oluşturulmuştur. $\mathrm{Bu}$ kısıt $\mathrm{BCC}$ modelindeki etkinlik sınırının, karar birimlerini birbirlerine daha yakın ve sıkı bir şekilde zarflamasını sağlamaktadır. $\mathrm{Bu}$ nedenle bir karar verme biriminin BCC'de etkin olması CCR modeline göre daha kolay ve olasıdır (Romana ve Guerrini, 2011). Dolayisiyla CCR modelinde etkin olarak elde edilen bir karar verme birimi BCC modelinde de etkindir. Fakat BCC modelinde etkin olan bir karar verme biriminin CCR'da etkin olması her durum için mümkün olmamaktadır. Ayrıca diğer modellerinde etkin sinırlarının konumları sebebiyle etkin bir sonuç elde edilmesi yüksek orandadır. Bu da kurulan modelin güvenilirliğinin sorgulanmasina sebep olur. CCR modeli VZA modelleri içerisinde gerçekçi sonuçlar üreterek en hassas etkinlik ölçümü gerçekleştirdiği (Lombardi vd., 2019) için bu çalışmada CCR modeli tercih edilmiştir.

VZA ile etkinliği ölçülen KVB'ler, girdileri çıtılara dönüştüren, performans1 değerlendirilmekte olan birimlerdir (Özdemir ve Demireli, 2013). VZA için KVB'ler yeterli sayıda olmalıdır. Cooper vd., (2007) serbestlik derecesi nedeniyle, KVB sayısının girdi ve çıktı sayısının en az iki katı kadar ya da girdi sayısı $m$, çıktı sayıs1 $s$, KVB sayıs1 da $n$ olmak üzere $n \geq$ $\max \{m \times s, 3(m+s)\}$ şeklinde olmasını önermiştir (Cooper vd., 2007).

VZA, her birim için bir etkinlik puanı sağlarken elde edilen etkinlik puanları arasında karşılaştırmay1 gerçekleştirmektedir. Etkin birimlerin verimli sınır elde edeceği ve etkin olmayan elemanların referans sınır kümeleriyle sarılacağı, emsal grubu karşılaştırmasına dayanmaktadır (Cooper vd., 2007). Verimlilik oranı genel bir biçimde aşağıdaki formülle belirlenmektedir:

Verimlilik $=\frac{\text { Çıtı ı Değerleri }}{\text { Girdi Değerleri }}$

Literatüre göre, herhangi bir özellikli birime ait etkinlik skoru 1'den büyük olamaz, dolayısılyla 1 'e eşit veya küçük olmalıdır. KVB'lerin göreli etkinlikleri 0 ile 1 arasındaki değerlerle gösterilmektedir. Bunun dışındakiler göreli olarak etkin olmayan KVB'lerdir (Cooper vd., 2007). 
$\frac{\text { Çıktı De ğerleri }}{\text { Girdi Değerleri }} \leq 1$

$\mathrm{Bu}$ formülün lineer faza geçişi şu şekildedir:

çıtıtı de ğerleri $\leq$ girdi değerleri

$\operatorname{Max} Z=\sum_{i=1}^{m} b_{i h} y_{i h} \quad h=1,2, \ldots, k$

$m=$ çıktı değişkenleri sayısı

$k=$ karar verme birimleri sayısı

Öyle ki;

$\sum_{i=1}^{n} a_{i h} x_{i h} \quad h=1,2, \ldots, k$

$n=$ girdi değișkenleri sayısı

$\sum_{i=1}^{n}\left(\sum_{i=1}^{n} a_{i h} x_{i h}-\sum_{i=1}^{m} b_{i h} y_{i h}\right) \leq 0$

$Z$ =Etkinlik Skoru

$x_{i h}=$ Karar verme birimi h için i'nin gözlemlenen girdi değeri

$y_{i h}=$ Karar verme birimi h için i'nin gözlemlenen çıktı değeri

$a_{i h}, b_{i h}=$ Karar verme birimi h için girdi ve çıktı ağırlık değerleri

Geleneksel VZA modelleri girdi odaklı ve çıktı odaklı iki gruba ayrılmaktadır. Eğer girdiler için kontrol az ise (ya da yoksa) çıktı odaklı, çıktılar üzerinde kontrol azsa (ya da yoksa) girdi odakl1 bir model kurulmalıdır. Girdi odaklı modelde etkin olmayan birimlerin etkin olabilmesi için çıktı değerleri korunurken girdiler oransal olarak azalmaktadır. Diğer taraftan, çıktı odaklı modelde etkin olmayan birimlerin verimli hale gelebilmesi için girdi değerleri sabit kalırken çıktı değerleri maksimize edilmeye çalışılır (Özden, 2008).

VZA yönteminin temel aşamaları sırasıyla aşağıdaki gibidir (Özdemir ve Demireli, 2013):

1. Karar birimlerinin belirlenmesi,

2. Girdi ve çıktı faktörlerinin belirlenmesi

3. Faktörlere ait verilerin elde edilmesi,

4. Modelin kurulması ve etkinlik ölçümü

5. Sonuçların değerlendirilmesi.

\section{Uygulama}

Bu bölümde öncelikle çalışmada yer alan KVB'ler olan mobil uygulamalar belirlenmiştir. Daha sonra VZA'da kullanılan girdi ve çıktı faktörleri belirlenerek bu faktörlere ilișkin verilerin elde edilmesi aşaması anlatılmıştır. Bir sonraki aşamada modelin kurulması verilmiş ve etkinlik ölçümü yapılarak sonuçlar değerlendirilmiştir.

\subsection{Karar Birimlerinin Belirlenmesi}

Çalışmada 3 girdi ve 3 çıktı kullanılmış ve üçüncü bölümde verilen formülden en az 18 adet KVB kullanılması gerektiği çıkmıştır. Bu nedenle Apple Store ve Google Play uygulama mağazalarında en çok kullanılan 21 adet mobil uygulama KVB olarak seçilmiştir.

\subsection{Girdi ve Çıktı Faktörlerinin Belirlenmesi}

Belirlenen girdi-çıktı değişkenleri, mobil uygulama firmalarının hizmet süreçlerini iyi bir şekilde temsil etmelidir. $\mathrm{Bu}$ nedenle çalışmada kullanılan girdiler kullanıcı arayüzü, uygulamanın kapladığı alan ve uygulamada geçirilen süre; çıtılar ise ciro, indirme sayısı ve görünürlüktür. Bilgiye kolayca ulaşılan günümüz dünyasında, karışık ve sıkıcı aşamaları içeren uygulamalar yerine yalın, anlaşılması kolay ve "kullanıcı dostu" uygulamalar geliştirebilmek, kullanıcıların etkileşimini arttırmada oldukça fazla önem taşımaktadır. $\mathrm{Bu}$ nedenle kullanıcı arayüzü tasarımı mobil uygulamalarda kritik bir faktör olarak görülmektedir. Uygulamada geçirilen süre ve uygulamanın kapladığı alan da kullanıcılar için oldukça önemlidir. Ciro, indirme sayısı, görünürlük, uygulamalar üzerinde başarıyı belirleyen finansal ve finansal olmayan faktörlerdir ve mobil uygulama analizi yapan şirketler tarafından da sıkça kullanılan performans ölçütleridir. Aşağıdaki kısımda da belirlenen girdi-çıktı değişkenlerinin detaylı tanımlarından verilmiştir.

\subsubsection{Girdiler}

Kullanıcı Arayüzü: Mobil cihazlar için kullanıcı arayüzleriyle ilgili teknolojileri açıklamaktadır. Kullanıcı arayüzü tasarımı mobil uygulamaların en önemli noktasıdır. Bu nedenle uygulamaların kullanılma amaçları ve özellikleri teknik tasarımdan çok önce iyice düşünülmelidir. Kullanıc1 arayüzlerinin kullanılabilir olması istenmektedir. Kullanılabilirlik, kullanıcı arayüzlerinin kullanımının ne kadar kolay olduğunu değerlendiren bir kalite özelliğidir. Ayrıca arayüzün kullanıcının istediğini hızlı ve doğal bir şekilde yapması yani işlevselliği de oldukça önemlidir. Kullanıcının verimli ve çabuk bir şekilde uygulamayı kullanabilmesi, uygulamayı kolayca öğrenmesi, kullanım memnuniyeti ve beklentilerinin karşılanması arayüzün başarısını göstermektedir. Tüm bunlar, 
uygulamanın kullanıcılar tarafindan kullanımının devam edip etmeyeceğini belirlemektedir (Naml, 2010; Nayebi vd., 2012; Nielsen, 2012).

Uygulamada Geçirilen Süre: Mobil telefon kullanıcılarının sahip oldukları mobil telefonlardaki uygulamada harcadığı zamandır. Günlük, haftalık ve aylık olarak ne kadar süre harcadıklarını öğrenmek için mobil telefonun ayarlar kısmından kolayca ulaşılabilmektedir (Özkoçak, 2016).

\section{Uygulamalarm Kapladıkları Alan:} Uygulamaları geliştirilebilmesi için cihazların yeterli kapasiteye sahip olmaları gereklidir. Ancak mobil cihazlar bu yönden kisitlı özelliklere sahiptir (Kes ve Kara, 2015). Buna rağmen ihtiyaç duyulan kullanım koşulları rahatlıkla sağlanabilmektedir. Verinin kullanılma şekli hafızada nasıl yer aldığ 1 , tavan yaptığı yerlerde sistemin davranışı ve uygulamanın veriyi nasıl yerleştirdiği ile ilgilidir. Bu nedenle, veri yapıları ve kullanılan hafıza daima dikkate alınmalıdır (Naml1, 2010).

\subsection{2. Çıktılar}

İndirme Sayısı: İnternette bulunan her türlü veri dosyasını bir bilgisayara ya da telefona transfer etme işlemidir. Yaygın kullanılan İngilizce karşıllı̆ına "download" adı verilmektedir. Bu veriler bilgisayara indirilmediği durumlarda, veriyi bilgisayarda ya da telefonunda görüntüleme işlemi esnasında da bir indirme işlemi gerçekleştirilmektedir (Mobilike, 2014).

Ciro: KVB tarafından günlük, haftalık, aylık veya y1llık şeklinde belirli bir zaman dilimi boyunca gerçekleştirilen faaliyetlerden elde edilen brüt gelir veya hasilat olup finansal analizlerde kullanılmaktadır (Candeğer, 2017).

Görünürlük: Bir kuruluş ya da uygulamanın internet üzerindeki görünürlüğünü ölçmek oldukça zordur. Öncelikle, internetin merkezi ve hiyerarşik bir yapısı olmadığ 1 için bu şekilde bir bilgi halihazırda yoktur. Ancak böyle bir bilgiye olabildiğince nesnel bir şekilde ulaşılmalıdır. İnternetteki görünürlük, yaygın kullanıcı tabanına sahip bir arama motorunun ilgili siteyi kaç arama sonucu döndürdüğü ile belirlenebilmektedir (Schmidbauer vd., 2007).

\subsection{Faktörlere İlişkin Verilerin Elde Edilmesi}

VZA yöntemi kullanılarak mobil uygulama alanında yapılan çalışmalarda kullanılan girdi ve çıtı değişkenleri incelenmiştir. Uygulamada 3 adet girdi ve 3 adet çıktı mobil uygulama etkinliğini yükseltme kriterlerine göre belirlenmiş olup veriler Tablo 1'de belirtilen sitelerden ve yapılan anket sonucu elde edilmiştir.

Tablo 1. Girdi ve çıktı değişkenleri

\begin{tabular}{ll}
\hline Girdi & Tanımlama \\
\hline Kullanıcı Arayüzü & Yapılan anket sonucunda alınan verilerden oluşturulmuştur. \\
Uygulamada Geçirilen Süre & Yapılan anket sonucunda alınan verilerden oluşturulmuştur. \\
Uygulamaların Kapladıkları Alan & 2019 Apple Store'daki verilerden alınmıştır. \\
\hline Çıktı & Tanımlama \\
\hline İndirme Sayısı & 2019 Şubat ayı verileri Mobileaction sitesinden alınmıştır. \\
Ciro & 2019 Şubat ayı verileri Mobileaction sitesinden alınmıştır. \\
Görünürlük & 2019 Şubat ayı verileri Mobileaction sitesinden alınmıştır. \\
\hline
\end{tabular}

Bu çalışmada 21 adet KVB bulunmaktadır. Yasal nedenlerle uygulamaların isimleri belirtilmemiş, bunun yerine çalışmada $U$ kodları ile temsil edilmişlerdir. Tablo 2'de KVB'lere ait girdi ve çıktı değişkenleri verilmiştir. Tablodaki kullanıcı arayüzü başlıklı sütunda 100 kişinin değerlendirmiş olduğu anket sonuçları görülmektedir. Kullanıcı arayüzü değerleri, anketi dolduranlar tarafindan 1 (çok kötü), 2 (kötü), 3 (orta), 4 (iyi), 5 (çok iyi) olarak değerlendirilmiş ve tüm sonuçların ağırlıklı ortalama puanları yazılmıştır. Bu doğrultuda en yüksek puanı U21 ve en düşük puanı ise U2 mobil uygulamasının aldığ1 gözlemlenmektedir. Anketin sağlıklı bir şekilde doldurabilmesi için anketi doldurmadan önce katılımcıların telefonlarındaki uygulama analizlerinden harcamış oldukları süreleri göz önünde bulundurmaları istenmiştir. Uygulamada geçirilen süre verileri kullanıcıların akıllı telefonlarındaki geribildirim istatistiklerinden gerçek tam sayı olarak alınmıştır. Anket aracılığıyla kullanıcılara telefonlarındaki bilgileri kontrol ederek verileri girmesi istenmiştir. Dolayısıyla bu değişken için kullanıcıların 
haftalık ortalama geçirmiş oldukları süreler saat biriminde alınarak analizde kullanılmıştır. Tablo 2'de sunulan haftalık geçirilen süre verileri 1şığında, kullanıcıların vakitlerinin çoğunu U3, U4 ve U8 uygulamalarında harcamış olduğu görülmektedir. Mobil uygulamaların mobil telefonlarda kapladıkları hafizaları, ilgili web sayfalarından bulunmuştur (Apple Store'dan alınmıştır.)

İnternetteki verilere göre 21 mobil uygulamadan en çok indirilen U4 kodlu uygulamadır. En çok ciroya sahip mobil uygulama aylik 99 milyon dolarla U8 olmuştur. En az ciroya sahip uygulama ise ayl1k 12 bin dolarla U17'dir. Mobil uygulamalar seçilirken sosyal medyada en popüler olan uygulamaları tercih edilmiştir. $\mathrm{Bu}$ yüzden görünürlük puanları ve oranları çok yüksektir. Kullanicilar, arama motoruna anahtar kelime yazdıklarında ilk sirada bu uygulamalarla karşılaşacaktır. U1 (96), U6 (95), U13 (89), U12 (98), U15 (89) ve U19 (76.5) hariç kalan 15 uygulamanın görünürlük oranları 100'dür.

Tablo 2. KVB'lere ait girdi-çıktı değiş̧kenleri

\begin{tabular}{|c|c|c|c|c|c|c|}
\hline \multirow[b]{2}{*}{ Uygulama } & \multicolumn{3}{|c|}{ Girdiler } & \multicolumn{3}{|c|}{ Çıktılar } \\
\hline & $\begin{array}{l}\text { Kullanıcı } \\
\text { arayüzü }\end{array}$ & $\begin{array}{c}\text { Haftalik } \\
\text { gecirilen } \\
\text { süre (saat) }\end{array}$ & $\begin{array}{l}\text { Kapladığı } \\
\text { alan (MB) }\end{array}$ & $\begin{array}{l}\text { İndirme } \\
\text { sayisi }\end{array}$ & Ciro (\$) & $\begin{array}{l}\text { Görünürlük } \\
(\%)\end{array}$ \\
\hline U1 & 4.05 & 2.58 & 78.10 & $15,000,000$ & $81,000,000$ & 96 \\
\hline $\mathrm{U} 2$ & 2.88 & 1.63 & 270.00 & $16,000,000$ & 561,000 & 100 \\
\hline U3 & 4.29 & 3.88 & 90.82 & $12,000,000$ & $7,000,000$ & 100 \\
\hline U4 & 4.13 & 3.76 & 87.10 & $30,000,000$ & $15,000,000$ & 100 \\
\hline U5 & 3.80 & 2.36 & 89.10 & $7,000,000$ & $4,000,000$ & 100 \\
\hline U6 & 3.82 & 2.27 & 109.80 & $5,000,000$ & 118,000 & 95 \\
\hline U7 & 3.47 & 1.41 & 56.80 & $1,351,000$ & $5,000,000$ & 100 \\
\hline U8 & 4.30 & 3.51 & 147.80 & $17,000,000$ & $99,000,000$ & 100 \\
\hline U9 & 2.92 & 1.19 & 124.00 & $9,000,000$ & 300,000 & 100 \\
\hline U10 & 4.10 & 1.70 & 172.70 & 164,0000 & 115,000 & 100 \\
\hline U11 & 3.96 & 1.34 & 69.50 & 311,000 & $5,000,000$ & 100 \\
\hline U12 & 3.26 & 1.20 & 73.50 & 269,000 & 73,000 & 98 \\
\hline U13 & 3.42 & 1.27 & 83.10 & $6,000,000$ & 120,000 & 89 \\
\hline U14 & 3.02 & 1.16 & 166.90 & $14,000,000$ & 141,000 & 100 \\
\hline U15 & 3.95 & 1.27 & 56.00 & $4,000,000$ & 148,000 & 89 \\
\hline U16 & 3.29 & 1.21 & 92.70 & $5,000,000$ & 393,000 & 100 \\
\hline U17 & 3.67 & 1.24 & 59.90 & 743,000 & 12,000 & 100 \\
\hline U18 & 3.21 & 2.29 & 892.00 & $3,287,000$ & $23,000,000$ & 100 \\
\hline U19 & 3.43 & 1.33 & 149.00 & $2,925,000$ & $12,000,000$ & 76.5 \\
\hline U20 & 3.02 & 1.25 & 100.80 & 50,000 & 27,000 & 100 \\
\hline U21 & 4.54 & 3.05 & 216.60 & $1,000,000$ & $2,000,000$ & 100 \\
\hline
\end{tabular}

\subsection{Modelin Kurulması ve Etkinlik Ölçümü}

Çalı̧̧mada incelenen firmaların, çıktıları arttırma yetenekleri vardır ve firmalar çıktı maksimizasyonu odaklı çalışmaktadırlar. $\mathrm{Bu}$ nedenle VZA için çıtı maksimizasyonu modeli uygun bulunmuş olup çıtı yönelimli CCR modeli tercih edilmiştir (Şekil 1).

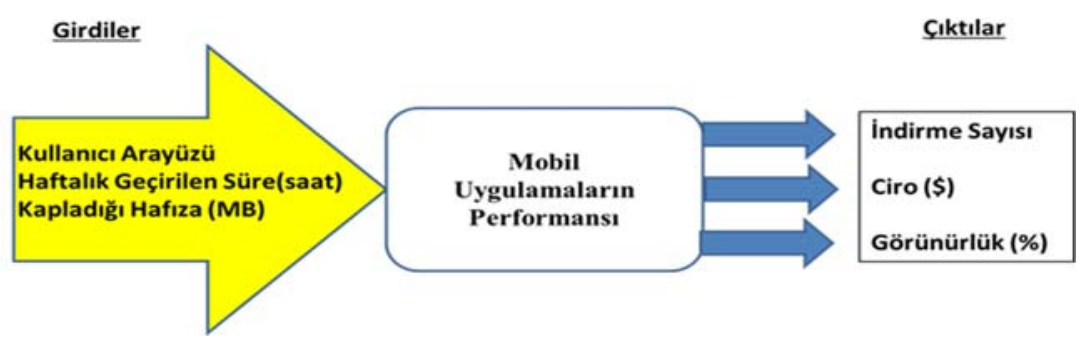

Şekil 1. Konsept Model 
$\mathrm{Bu}$ çalışmada Apple Store ve Google Play uygulama mağazalarında en çok kullanılan uygulamaların görece etkinlik skorları, DEA Solver programı ile CCR modelleri yardımıyla hesaplanmıştır. Girdi ve çıktılar, teknik açıdan mümkün ve anlamlı olarak oluşturulmaya çalışılmış, girdilerin istenen çıktıyı karşılayabilecek yeterlilikte olmasına dikkat edilmiştir. Önerilen modelin temel amaci mobil uygulamaların etkin olup olmadığını bulmaktır. Dolayısıyla modelde amaç fonksiyonunun değeri l'e eşitse, mobil uygulama etkin olarak tanımlanmakta; eğer bu değer 1'den küçük ise, verimsiz bir uygulama olarak tanımlanmaktadır.

\subsection{Sonuçların Değerlendirilmesi.}

Toplanan veriler DEA Solver programı ile analiz edilmiş ve sonuçlar bulunmuştur. Tablo 3 'te değişkenlere ait en az, en çok, ortalama ve standart sapma başlıkları altında açıklamalı istatistik değerleri verilmiştir. Girdi ve çıktı değişkenlerinin arasındaki korelasyon katsayısı (r) değerleri de hesaplanarak Tablo 4'te sunulmuştur.

Tablo 3. Girdi/çıktı oranlarının istatistikleri

\begin{tabular}{lllllll}
\hline & $\begin{array}{l}\text { Kullanıc1 } \\
\text { arayüzü }\end{array}$ & $\begin{array}{l}\text { Haftalık } \\
\text { geçirilen } \\
\text { süre (saat) }\end{array}$ & $\begin{array}{l}\text { Kapladıları İndirme } \\
\text { alan (MB) }\end{array}$ & $\begin{array}{l}\text { sayıs1 } \\
\text { Ciro (\$) }\end{array}$ & $\begin{array}{l}\text { Görünürlük } \\
(\%)\end{array}$ \\
\hline En çok & 4.54 & 3.88 & 892 & $30,000,000$ & $99,000,000$ & 100 \\
En az & 2.88 & 1.16 & 56 & 50,000 & 12,000 & 76.5 \\
Ortalama & 3.644 & 1.947 & 151.723 & $7,147,619$ & $12,143,238$ & 97.309 \\
Standart sapma & 0.487 & 0.896 & 174.154 & $7,534,296$ & $26,079,572$ & 5.720 \\
\hline
\end{tabular}

Korelasyon katsayısının negatif olması iki değişken arasında ters ilişki olduğunu göstermektedir ve "değişkenlerden biri artarken diğeri azalmaktadır" şeklinde yorumlanmaktadır. Korelasyon katsayısının pozitif olması durumunda ise "değişkenlerden biri artarken diğeri de artmaktadır" şeklinde yorumu yapılmaktadır. Korelasyon katsayısı 0.2 'den küçük ise "çok zayıf ilişki ya da korelasyon yok", 0.2-0.4 arasında ise "zayıf korelasyon", 0.4-0.6 arasinda ise "orta şiddette korelasyon", 0.6-0.8 arasında ise "yüksek korelasyon" ve 0.8 'den büyük ise "çok yüksek korelasyon" olduğu şeklinde yorumlanmaktadır (Yıldız ve Güneş, 2017). Buna göre kullanıcı arayüzü ile uygulamada geçirilen süre arasında 0.7071 korelasyon katsayıs ile yüksek korelasyon vardır. Yani kullanıcı arayüzünün kullanışlılığının artmas1, uygulamada geçirilen süreyi arttıracaktır. Kullanıcı arayüzü ile uygulamaların kapladıkları hafiza arasında -0.2223 korelasyon katsayılı ters ilişki vardır. Buna göre de uygulamanın kapladığı hafiza arttıkça kullanıcı arayüzü daha da karmaşık hale gelecektir. İndirme sayısı ve uygulamaların kapladıkları hafiza arasında -0.0535 korelasyon katsayılı ters ilişki mevcuttur. Uygulamanın kapladığ1 hafiza ne kadar fazla olursa uygulamanın indirilme sayıs1 azalmaktadır. Uygulamanın görünürlüğü ile cirosu arasında 0.0243 şeklinde zayıf korelasyon katsayısı vardır. Uygulamanin cirosu ne kadar fazlaysa görünürlüğü de o kadar fazladır.

Tablo 4. Girdi ve çıktıların korelasyon matrisi

\begin{tabular}{lllllll}
\hline & $\begin{array}{l}\text { Kullanıcı } \\
\text { arayüzü }\end{array}$ & $\begin{array}{l}\text { Haftalık } \\
\text { geçirilen } \\
\text { süre (saat) }\end{array}$ & $\begin{array}{l}\text { Kapladıkları } \\
\text { alan (MB) }\end{array}$ & $\begin{array}{l}\text { İndirme } \\
\text { sayısı }\end{array}$ & Ciro (\$) & $\begin{array}{l}\text { Görünürlük } \\
(\%)\end{array}$ \\
\hline Kullanıcı arayüzü & 1 & 0.7072 & -0.2224 & 0.1402 & 0.3723 & 0.0411 \\
Haftalık geçirilen süre & 0.7072 & 1 & 0.1162 & 0.5882 & 0.4973 & 0.2487 \\
Kapladıkları hafiza & -0.2224 & 0.1162 & 1 & -0.0535 & 0.0864 & 0.1210 \\
İndirme sayısı & 0.1402 & 0.5882 & -0.0535 & 1 & 0.4304 & 0.1542 \\
Ciro & 0.3723 & 0.4973 & 0.0864 & 0.4304 & 1 & 0.0244 \\
Görünürlük & 0.0411 & 0.2487 & 0.1210 & 0.1542 & 0.0244 & 1 \\
\hline
\end{tabular}

Yapılan analiz sonucunda elde edilen etkinlik puanları Tablo 5'te sunulmuştur. Etkinlik istatistiklerine göre puanların ortalaması 0.936 olarak elde edilmiştir. $\mathrm{Bu}$ değerlerin standart sapmas1 0.105 , maksimum değeri 1 ve minimum değeri ise 0.647 olarak bulunmuştur. Ortalama 
değerin yüksek olmasının sebebi KVB'lerinin $\% 50$ 'den fazlasının göreceli olarak verimli bir uygulama olmasindan kaynaklanmaktadır. Standart sapma değerinin de 0.105 değerine sahip olması genel etkinlik puanlarının dağılım aralığının dar olmasındandır. Nitekim maksimum ve minimum etkinlik puanı arasında 0.357 değerinde bir fark gözlemlenmektedir. Diğer taraftan ise etkin olmayan firmaların hali hazırda referans kümelerinde $\mathrm{ki}$ uygulamalar ile karşılaştırma yapılarak verimli bir uygulamaya gelmeleri için mutlak iyileştirilmeleri gerekmektedir.

Tablo 5. KVB'lerin etkinlik puanları

\begin{tabular}{|c|c|c|c|c|c|}
\hline KVB & Etkinlik Skoru & KVB & Etkinlik Skoru & KVB & Etkinlik Skoru \\
\hline U1 & 1 & U8 & 1 & U15 & 1 \\
\hline $\mathrm{U} 2$ & 1 & U9 & 1 & U16 & 1 \\
\hline U3 & 0.842 & U10 & 0.713 & U17 & 1 \\
\hline U4 & 1 & U11 & 0.983 & U18 & 0.998 \\
\hline U5 & 0.893 & U12 & 1 & U19 & 0.829 \\
\hline U6 & 0.792 & U13 & 0.959 & $\mathrm{U} 20$ & 1 \\
\hline U7 & 1 & U14 & 1 & $\mathrm{U} 21$ & 0.647 \\
\hline
\end{tabular}

Kıyaslama aşamasında, etkin olmayan her bir karar birimi ayrı ayrı incelenerek, bunların etkin hale gelebilmesi için ne gibi iyileştirmelerin yapılması gerektiği belirlenmektedir. VZA, etkin olmayan KVB'lerin, göreli olarak etkin KVB'lerin uyguladığı yöntemleri uygulayarak, girdi-çıktı değerlerinde yapılabilecek değişiklikler ile etkin KVB'lerle aynı etkinlik düzeyine ulaşabilecekleri varsayımı üzerine kurulmuştur. Kıyaslama için referans kümesi frekanslarına bakılmış ve Tablo 6'da verilmiştir.

Tablo 6. Referans kümesi frekans1

\begin{tabular}{cc}
\hline Referans & Diğer KVB'lerindeki sıklık \\
\hline U1 & 2 \\
U2 & 2 \\
U4 & 3 \\
U7 & 3 \\
U8 & 2 \\
U9 & 6 \\
U14 & 1 \\
U15 & 1 \\
U16 & 2 \\
U17 & 1 \\
U20 & 2 \\
\hline
\end{tabular}

Tabloda uygulamaların diğer firmalara örnek olarak gösterildiği sayılar görülmektedir. Örneğin U1 verimli bir mobil uygulamadır. Bu uygulama diğer verimsiz mobil uygulamaların referans setinde 2 defa yer almıştır.
Etkin olmayan uygulamaların referans seti ise Tablo 7'de verilmiştir. U13 uygulaması referans setinde 4 farklı uygulamayla kiyaslama yapılırken U10, U18 ve U19 uygulamalarının referans setinde 2 farklı uygulama görülmektedir.

Etkin olmayan her bir uygulamanın referans setlerindeki uygulamalara ait girdi ve çıktı değerlerine atanan ağırlık değerleriyle çarpılması ve ulaşılan değerlerin toplanmasıyla etkin olmayan her bir uygulamanın optimum girdi ve çıtı değerleri hesaplanmaktadır. Elde edilen optimum girdi ve çıktı değerleri etkin olmayan uygulamanın hedeflenen değeri olarak da tanımlanır.

Tablo 7. Etkin olmayan uygulamaların referans seti

\begin{tabular}{|l|l|}
\hline $\begin{array}{l}\text { Etkin Olmayan } \\
\text { Mobil Uygulama }\end{array}$ & Referans Seti \\
\hline U3 & U4, U7, U9 \\
\hline U5 & U4, U7, U9 \\
\hline U6 & U7, U9, U20 \\
\hline U10 & U9, U20 \\
\hline U11 & U1, U16, U17 \\
\hline U13 & U4, U9, U15, U16 \\
\hline U18 & U2, U8 \\
\hline U19 & U1, U14 \\
\hline U21 & U2, U8, U9 \\
\hline
\end{tabular}

\section{Analiz ve Bulgular}

Önerilen modelde çıktı değerlerini maksimize ederek karar birimlerini verimli seviyeye ulaştırma hedefi doğrultusunda çıktı odaklı CCR 
modeli kullanılmıştır. Bu nedenle birçok etkinlik analizinde kullanıldığ 1 gibi DEA Solver programı kullanılarak çıktı odaklı CCR modeli çalıştırılmıştır.

Bütün uygulamaların birlikte analiz edilerek elde edilen etkinlik puanlarına bakıldığında farklı verimlilik alanlarına dağıldığı gözlemlenmiştir. Şekil 2'de görüldüğü üzere 0.8 etkinlik puanının altında 3 uygulama ve 0.9 etkinlik puanının altında 6 uygulama olduğu görülmektedir. Bununla birlikte 9 uygulamanın etkinlik puanı 1'in altında elde edilmiş ve bu değer aynı zamanda verimsiz uygulama sayısına işaret etmektedir. Diğer taraftan geriye kalan 12 firma ise "1" etkinlik puanını elde ederek tüm uygulamaların içinde göreceli olarak verimli ve etkin uygulama kategorisi içinde yer almışlardır.

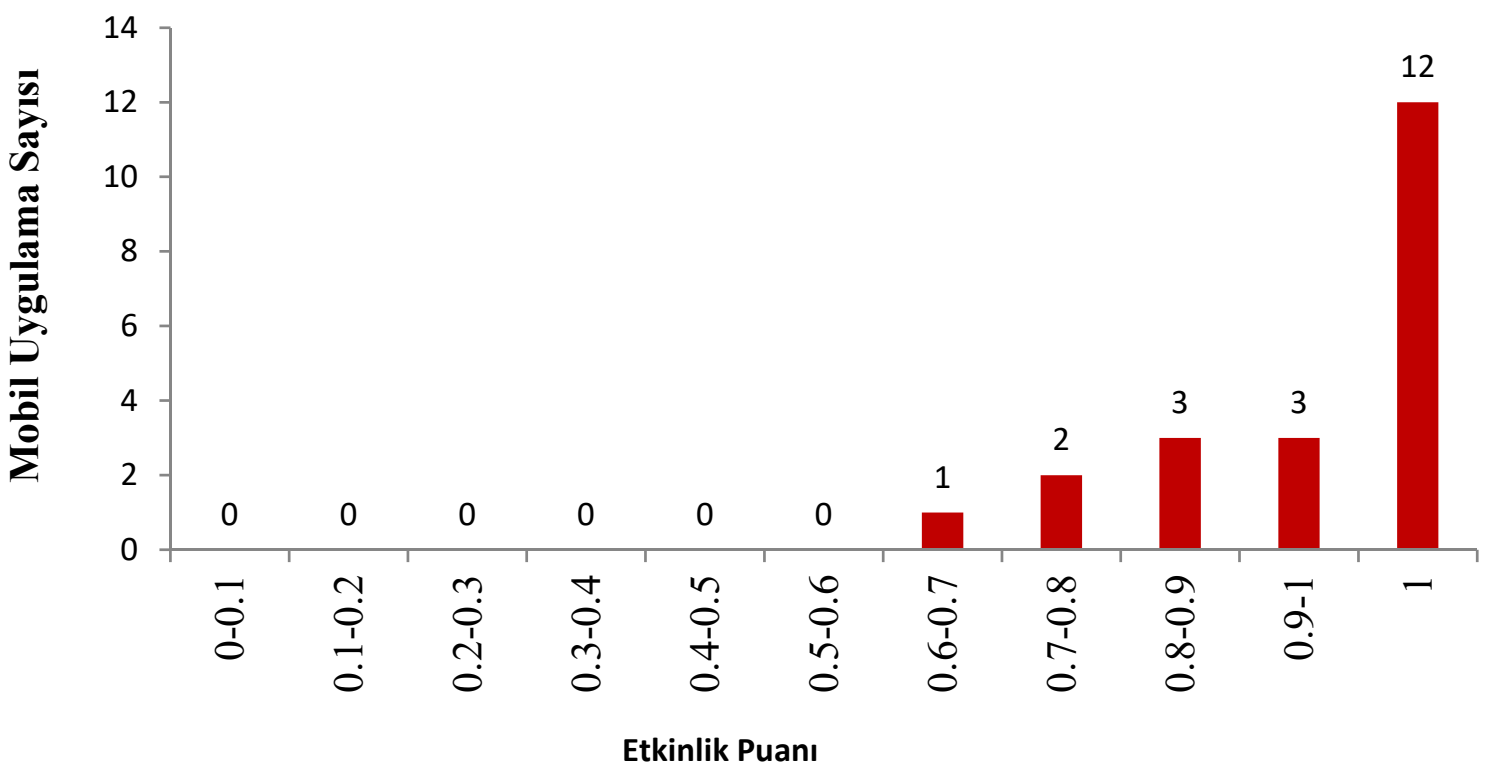

Şekil 2. Mobil uygulamaların genel etkinlik analizi

Tüm uygulamaların etkinlik puanları dikkate alındığında KVB'lere ait ağırlıklı ortalama 0.93 olarak bulunmuştur. Sonuçlara göre 6 uygulama ortalamanın altında etkinlik puanına sahip olmuşlardır. Bunun başlica nedenlerden biri modelde yer alan çıktı değișkenlerinin özellikle finansal performansı ölçen kriterlerden biri olan cironun istenilen seviyelerde olmamasındandır. Ayrıca Şekil 3'te görüldügü gibi toplam olarak 21 uygulamada ortalama \%1.95 kullanıcı arayüzü, $\% 3.77$ kapladıkları hafiza ve \%6.42 haftalık geçirilen süre bazında optimum seviyenin üstü rakamlar gözlemlenmektedir.

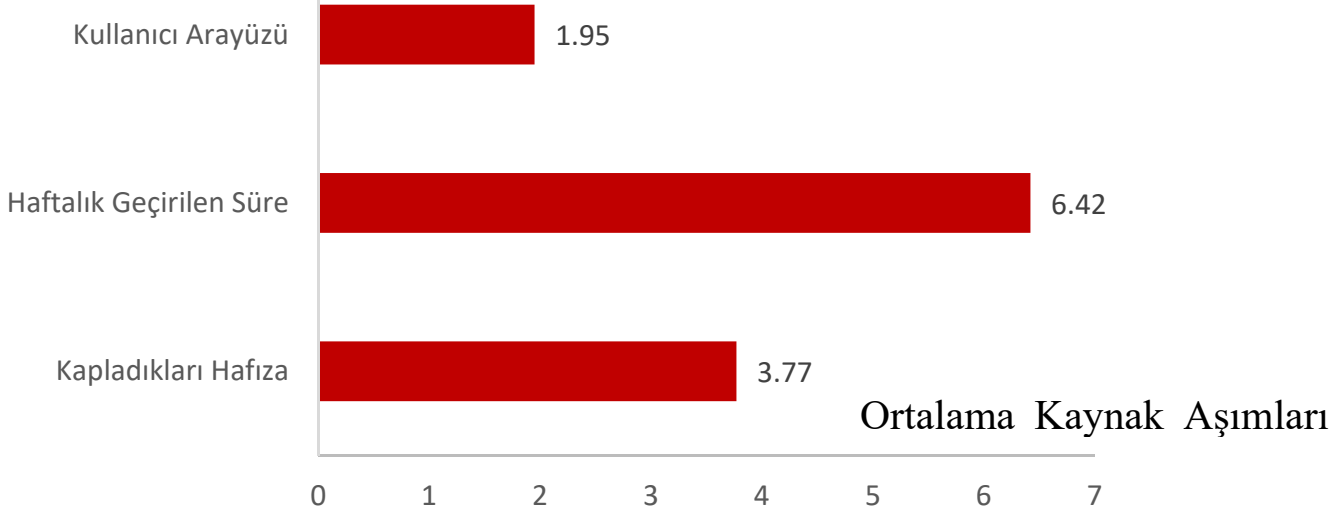

Şekil 3. Mobil uygulamaların ortalama kaynak aşımları 
Diğer taraftan indirme sayıs1, ciro ve görünürlük puanındaki düşük değerler çıktı seviyelerinin yetersizliğine ve dolayısıyla verimsizliğe neden olmuştur. $\mathrm{Bu}$ nedenle uygulamalar verimli hale gelebilmek için genel olarak indirme sayılarını $\% 18.91$, cirolarını \%14.35 ve son olarak görünürlüklerini $\% 8.48$ seviyesinde arttırmaları gerekmektedir. Analitik açıdan bakıldığında verimsiz firmaların başarıya ulaşabilmeleri için girdi ve çıktı değerleri dikkate alınmalı ve yapılacak iyileştirmeler veriler üzerinden değerlendirilmelidir. Örneğin, 0.64 etkinlik puanına sahip olan en verimsiz uygulamaya ait optimum kaynak seviyesi ve çıtı eksiklikleri Tablo 8'de verilmiştir.
Kurulan model doğrultusunda çıtı odaklı yapılan analiz öncelikle verimsizliğe neden olan çıktılardaki eksiklikleri bulmaya odaklanmıştır. Daha sonra ise girdi fazlalıkları hesaplanmıştır. Dikkate aldığımız en verimsiz uygulamayı incelediğimizde bu uygulamanın referans kümesinde 3 adet uygulamanın olduğu görülmüştür. Uygulamaların girdi ve çıktı değerlerine atanan ağırlıklar ise sirasıyla 0.16 , 0.12 ve 1.35 olarak bulunmuştur. Dolayisiyla firmanın verimli hale gelebilmesi için kıyaslama yapılan diğer 3 firmanın girdi ve çıktı değerleriyle atanan ağırlıkların çarpılması sonucunda elde edilen değerler toplanır ve firmaya ait optimum girdi-çıktı değerleri hesaplanır. Tablo 8'de ulaşılan toplam değerler verimsiz firmaya ait verimli uygulama değerleridir.

Tablo 8. En verimsiz uygulamaya ait değişken değerleri

\begin{tabular}{|c|c|c|c|c|}
\hline & $\begin{array}{l}\text { En verimsiz } \\
\text { uygulama }\end{array}$ & $\begin{array}{l}\text { Kaynak } \\
\text { Aşımları (\%) }\end{array}$ & $\begin{array}{l}\text { Çıktı } \\
\text { Eksiklikleri } \\
(\%)\end{array}$ & $\begin{array}{l}\text { Hedef } \\
\text { Değer }\end{array}$ \\
\hline \multicolumn{5}{|l|}{ Girdiler } \\
\hline $\begin{array}{l}\text { Kullanıcı } \\
\text { Arayüzü }\end{array}$ & 4.54 & - & & - \\
\hline $\begin{array}{l}\text { Haftalık } \\
\text { Geçirilen } \quad \text { Süre } \\
\text { (saat) }\end{array}$ & 3.05 & 35.33 & & 1.97 \\
\hline $\begin{array}{l}\text { Kapladıkları } \\
\text { Hafıza }\end{array}$ & 216.6 & - & & - \\
\hline \multicolumn{5}{|l|}{ Çıktılar } \\
\hline İndirme Say1s1 & $1,000,000$ & & 52.83 & $1,528,319$ \\
\hline Ciro $(\$)$ & $2,000,000$ & & 54.47 & $3,089,443$ \\
\hline Görünürlük & 100 & & 54 & 154 \\
\hline
\end{tabular}

Kaynak aşımları ve çıktı eksiklikleri analiz sonuçlarından belirlenerek Tablo 8'de gösterilmiştir. Verimsiz uygulamaya ait kullanılan model değişkenleri verimli bir birim haline gelinebilmesi için iyileştirilmelidir. Örneğin, kaynak kullanımı açısından, uygulamada haftalık geçirilen süre 3.05 saatten 1.97 saate düşürülmelidir. Çünkü bu değişkene ait \%35.33'lük bir seviye aşımı gözlemlenmiştir. Kullanıcılar uygulamaları ilk kullanmaya başladıkları zaman uygulamanın sağladığ 1 özellikler doğrultusunda ilgili uygulamayı daha etkin bir şekilde kullanmaktadır. Fakat programda geçirilen süre arttıkça insanlardaki mental yorgunluk sebebiyle uygulamanın etkinliği ve kullanılabilirlik seviyesi zamanla düşmektedir (Esgin vd., 2011). Buna göre verimsiz olan uygulamalarda geçirilmesi beklenen ideal süreler bazı uygulamalar için düzeltilmiş ve iyileştirilmiştir. Diğer taraftan, bu uygulamaya ait finansal performans kriterlerinden biri olan ciro miktarı 2,000,000'dan 3,089,443'e arttır1malıdır. Aynı zamanda verimli bir uygulama seviyesi için Tablo 8'de görüldüğü üzere indirme sayıs1 $1,000,000$ 'dan 1,528,319'a yükseltilmeli ve görünürlük seviyesi 100'den 154'e çıkarılmalıdır.

\section{Değerlendirme}

Teknolojik gelişmelere bağlı olarak tüketicilerin talep ve ihtiyaçlarının değişmesi ve cep telefonu kullanımının artması sonucu meydana gelen mobil devrim, mobil yaşam ve/veya yaşam tarzı, günümüzde önemli bir konu haline gelmiştir. İşletmelerin rekabet üstünlügü sağlamaları ve faaliyetlerini güvenilir bir şekilde sürdürmeleri için yeni teknolojileri yakından takip etmeleri ve bu değişiklikleri uygulamaları gerekir.

Mobil iletişim teknolojisindeki gelişmeler, cep telefonlarının fonksiyonlarının artması, mobil ticaretin hızlı büyümesi, yaşanan gelişmelerin 
işletmelerin ticari faaliyetlerini etkilemesi ve müşterilerin satın alma alışkanlıklarına yeni bir boyut kazandırmasıla birlikte mobil uygulamaların önemi daha fazla artmıştır. Sanal yaşamın ön plana çıkmasıyla birlikte mobil uygulamalar ürünlerin satış rakamlarını arttırarak pozitif anlamda katkı sağlamakta diğer taraftan ise kullanıcıların hayatında sosyolojik açıdan bazı negatif sonuçlar doğurabilmektedir. Mobil uygulamalar, şu anda oluşturdukları ve gelecekte yapacakları etkiler bakımından olumlu ve olumsuz olarak iki kategoride değerlendirilebilir. Altman (2004) bu yönüyle mobil uygulamaların olumlu ve olumsuz noktalarının özellikle tatil alışkanlıkları ve satın alma davranışları üzerine daha fazla etkilerinin olacağını belirtmektedir.

Teknolojinin gelişmesiyle birlikte ortaya çıkan ak1llı telefonlar, tabletler ve diğer dijital ürünler toplumun kendisini modern teknoloji gerekliliklerine göre yeni gelişmelere uyum sağlamalarını gerekli kılmıştır. $\mathrm{Bu}$ ürünlerin işlevsel hale gelmesinde mobil uygulamaların etkin bir şekilde kullanımı önemli hale gelmiştir. Artık insanlar çevrimiçi ödemeler yapmakta, sanal organizasyonlar düzenlemekte, yine çevrimiçi toplantılar ve seminerler gerçekleştirmektedir. $\mathrm{Bu}$ durumla ilişkili olarak program geliştiriciler ve tasarımcılar daha çok proje ve uygulama geliştirmektedir. Geliştirilen uygulamaların etkinliğinin değerlendirilmesi ise kritik bir hal almıştır. Birçok uygulamanın alternatifi olduğundan kullanışlı bir şekilde geliştirilemeyen ve kullanici dostu olmayan uygulamalar kullanıcılar tarafindan verimli, etkin ve tatmin edici bulunmadığı takdirde bir daha kullanılmamaktadır. $\mathrm{Bu}$ sebeple mobil uygulamaların girdi-çıktı bazında etkinliğinin ölçülmesi uygulamanın kullanışlılık derecesinin de değerlendirilmesinde rol oynamaktadır. Etkin bir uygulama diğer ürünlere benzer bir şekilde çevresel, ekonomik ve sosyal faktörlerle uyumlu halde pazarda var olmaya ve büyümeye devam edecektir.

$\mathrm{Bu}$ çalışmada akıllı telefonlar ve tabletlerin yaşamımızda sıkça kullanılmasıyla birlikte geliştirilen mobil uygulamaların etkinlik analizi yapılmıştır. Değerlendirmeye alınan mobil uygulamalar günümüzde kullanılan en popüler uygulamalar olup günlük yaşantımızda gerçekleştirmiş olduğumuz görevleri yerine getirmede sıkça kullanılan araçlardır. Seçilen uygulamaların daha etkin bir seviyeye getirilmesi ve performanslarının iyileştirilmesi amacıyla kaynak bazlı değerlendirmeleri yapılmıştır. $\mathrm{Bu}$ doğrultuda çıktı odaklı VZA modeli kullanılarak mobil uygulamaların göreceli etkinlik değerleri hesaplanmıştır. Bu çalışmanın yapmış olduğu en önemli katkı ise uygulamaları kullanan kişilerin çalışmaya dahil edilmiş olması ile kullanıcıların değerlendirmelerinin analize dahil edilmesi ve objektif verilerle birleştirilerek bütüncül bir çalışma halinde sunulmasıdır.

Çalışmanın ilk aşamasında 21 farklı mobil uygulamaların etkinlik analizi VZA kullanılarak gerçekleştirilmiştir. Sonuçlar, değerlendirilen uygulamaların \%57'sinin verimli bir şekilde kaynaklarını kullanarak maksimum çıktıları elde ettiklerini göstermektedir. Konsept olarak "kaynakların verimli kullanılması" sadece çıktıların maksimum seviyeye getirilmesini değil aynı zamanda kaynakların optimum bir seviyede kullanılarak girdi-çıktı dengesini oluşturmayı amaçlar. Diğer taraftan, uygulamaların \%29'u ortalama etkinlik puanı olan 0.93 değerinden daha az etkinlik puanına sahiptirler.

Mobil uygulamaların kullanıldığı akıllı telefonlar ve tabletlerin kullanıcıların büyük bir bölümü satın alacağı ürünün kapasitesine bakmaktadır. Geliştirilen uygulamalar eskiye kıyasla daha fazla yer kapladığından akıllı telefonlarda ve tabletlerde saklama alanı problemiyle karşılaşan kullanıcı sayısı daha fazladır. Kapasite oranının ürün fiyatıyla doğru orantılı olduğu dijital ürün endüstrisinde ürünlerin fiyatları ise günden güne artmaktadır. Mobil uygulamaların yanı sıra yüksek çözünürlüklü fotoğraflar ve videolarda saklama alanının kısa sürede dolmasına sebep olmaktadır. Özellikle günümüzde $16 \mathrm{~GB}$ ve 32 GB dahili hafızalı ürünlerin kullanıcıları başta mobil uygulamalar olmak üzere birçok veriyi silmek zorunda kalmaktadır. Çalışmada elde edilen analiz sonuçlarına göre de incelenen ürünler ortalama \%3.77'lik fazla alan kaplamaktadır. Dolayısıyla mobil uygulamaların sürdürülebilirliğinin sağlanması adına kapladıkları hafiza noktasında iyileştirme yapılması gereklidir. Özellikle uygulama geliştiricilerinin sundukları uygulamanın içeriğinde kullanıcıların gerçekleştirmek istedikleri göreve odaklı özellikleri uygulamaya dahil etmesi daha uygun olacaktır.

Sunulan VZA modeli, etkinlik skorlarını baz alarak bu doğrultuda göreceli kıyaslama yapan ve mobil uygulama verimliliklerini hesaplayan bir modeldir. Teorik olarak girdi değerlerini sabit tutarak çıktı değerlerini arttırmak, mobil uygulamaların verimli bir şekilde performans göstermelerini sağlayabilir ancak gerçek yaşamda pratik olarak bu durumun gerçekleşmesi zaman 
alıc1 bir süreçtir. $\mathrm{Bu}$ doğrultuda, mobil uygulamalara ait performans kriterleri iyice tahlil edilerek etkin bir yönetim şekli benimsenmelidir.

Gelecekte yapılacak çalışmalarda, sunulan model genişletilerek daha çok girdi-çıktı değişkenleriyle farklı analizler gerçekleştirilebilir. Ayrıca, değerlendirilecek olan mobil uygulama sayıs1 artırılarak daha çok uygulamanın performansları ölçülebilir ve uygulama geliştiricilere ve tasarımcılara performansın iyileştirilmesi adına yol haritası sunulabilir.

\section{Kaynaklar}

Bakırcı, F., 2006. Sektörel Bazda Bir Etkinlik Ölçümü: VZA ile Bir Analiz. İktisadi ve İdari Bilimler Dergisi, 20(2), 199-217.

Banker, R.D., Charnes, A., Cooper, W.W., 1984. Some Models for Estimating Technical and Scale Inefficiencies in Data Envelopment Analysis. Management Science, 30(9), 1078-1092.

Candeğer, K.C., 2017. Mühendisler ve Ekonomi. Türk Mühendis ve Mimar Odaları Birliği Metalurji ve Malzeme Mühendisleri Odası Dergisi, Metalurji,184, 31-35.

Charnes, A., Cooper, W.W., Rhodes, E.L., 1978. Measuring the Efficiency of Decision Making Units. European Journal of Operational Research, 2, 429-444.

Charnes, A., Cooper W.W., Lewin, A.Y. ve Seifod, L.M., 1994. Data Envelopment Analysis: Theory, Methodology and Applications: Boston, Kluwer Akademic Publishers.

Chatzigeorgiou, A. ve Stiakakis, E., 2011. Benchmarking Library and Application Software with Data Envelopment Analysis. Software Quality Journal, 19, 553-578.

Cooka, W.D. ve Seiford, L.M., 2009. Data Envelopment Analysis (DEA). Thirty Years on. European Journal of Operational Research, 192, $1-17$.

Cooper, W., Seiford, W., L.M ve Tone, K, 2007. Data Envelopment Analysis: A Comprehensive Text with Models, Applications, References and DEA-Solver Software: New York, USA, Springer.

Çağıl, G. ve Bahadır, G., 2018. Sakarya Üniversitesi Mühendislik Fakültesi Bölümlerin Veri Zarflama Analizi ile Karşılaştırmalı Etkinlik Ölçümü. Uluslararası Mühendislik Araştırma ve Geliştirme Dergisi, 10(1), 139-147.

Depren, Ö., 2008. Veri Zarflama Analizi ve Bir Uygulama. Basılmamış Yüksek Lisans Tezi,
Yıldız Teknik Üniversitesi Fen Bilimleri Enstitüsü. İstanbul, 128s.

Ercan, E. (2015, $7 \quad$ Nisan). https://www.stradiji.com/hangisi-daha-karlimobil-site-vs-mobil-uygulama.

Esgin, E., Şakar, I.D, Torun, E., Doğan, C. ve. Yardım, MS, 2011. İnternet Kullanımının İlköğretim Öğrencilerinin Psiko-Sosyal Gelişimlerine Olumsuz Etkileri. Eğitim Teknolojileri Araştırma Derneği, 3(4), 1681.

Farrell M.J., 1957. The Measurement of Productive Efficiency. Journal of the Royal Statistical Society, 120, 253-290.

Guo B., Ouyang, Y., Guo, T., Cao, L. ve Yu, Z., 2019. Enhancing Mobile App User Understanding and Marketing With Heterogeneous Crowdsourced Data: A Review. IEEE Access, 7, 68557-68571.

Hwang, Y., Lee, D. ve Jung, K., 2019. Mobile App Recommendation with Sequential App Usage Behavior Tracking. Journal of Internet Technology, 20(3), 827-837.

Jabangwe R., Edison, H. ve Duc N.A., 2018. Software Engineering Process Models for Mobile App Development: A Systematic Literature Review. The Journal of Systems \& Software, 145, 98111.

Karakış, E. 2011. Emniyet Güçlerinin Performansını Veri Zarflama Analizi ile Değerlendirme. Basılmamış Yüksek Lisans Tezi, Gazi Üniversitesi Fen Bilimleri Enstitüsü. Ankara.

Kaur, A. ve Kaur, K., 2019. Investigation on Test Effort Estimation of Mobile Applications: Systematic Literature Review and Survey. Information and Software Technology, 110, 5677.

Kes. Y ve Kara, M., 2015. Mobil Oyun Geliştirme Sürecinde Arayüz Tasarımı. Yıldız Journal of Art and Design, 2(2), 18-26.

Liu J.S., Lu, L.Y.Y. ve Lu, W., 2016. Research Fronts in Data Envelopment Analysis. Omega, 58, $33-$ 45.

Lombardi, G.V., Stefani, G., Paci, A., Becagli, C., Miliacca, M., Gastaldi, M., Giannetti, B.F. ve Almeida, C.M.V.B. 2019. The Sustainability of the Italian Water Sector: An Empirical Analysis by DEA. Journal of Cleaner Production, 227(1), 1035-1043.

Mobilike, 2014. MadReport e-Dergisi, Q2, 2014 https://pdfslide.net/mobile/madreport-q22014.html.

Naml, Ç., 2010. Mobil Uygulama Kullanılabilirliğinin Değerlendirilmesi. Yüksek Lisans Tezi, İstanbul 
Teknik Üniversitesi Fen Bilimleri Enstitüsü, İstanbul, 122s.

Nayebi, F., Desharnais, J. ve Abran, A., 2012. The State of the Art of Mobile Application Usability Evaluation. 25 $5^{\text {th }}$ IEEE Canadian Conference on Electrical and Computer Engineering (CCECE).

Nielsen, J., 2012. Usability 101: Introduction to Usability. Retrieved From, http:/www. nngroup. com/articles/usability-101introduction-to-usability.

Özdemir, A. ve Demireli, E., 2013. Ağırlık Kısıtlı Veri Zarflama Analizi ile Mevduat Bankalarının Etkinlik Ölçümüne Yönelik Bir Uygulama. Uluslararası Yönetim İktisat ve İşletme Dergisi, 9(19), 215-238.

Özden, Ü.H., 2008. Veri Zarflama Analizi (VZA) ile Türkiye'deki Vakıf Üniversitelerinin Etkinliğinin Ölçülmesi. İstanbul Üniversitesi İşletme Fakültesi Dergisi, 37(2), 167-185.

Özkoçak Y., 2016. Türkiye'de Akıllı Telefon Kullanıcılarının Oyalanma Amaçlı Tercih Ettikleri Mobil Uygulamalar. Global Media Journal: Turkish Edition, 6(12), 106-130.

Petersen K., 2011. Measuring and Predicting Software Productivity: A Systematic Map and Review. Information and Software Technology, 53, 317343.

Romano, G. ve Guerrini, A. 2011. Measuring and Comparing the Efficiency of Water Utility Companies: A Data Envelopment Analysis Approach. Utilities Policy, 19(3), 202-209.

Sarı, Z., 2015. Veri Zarflama Analizi ve Bir Uygulama. Yüksek Lisans Tezi, Hacettepe Üniversitesi Fen Bilimleri Enstitüsü, Ankara, 84s.
Sayım, F. ve Aydın, V., 2011. Hizmet Sektörü Özellikleri ve Sistematik Olmayan Risklerin Sektör Menkul Kıymetleri ile Etkileșimine Dair Teorik Bir Çalışma. Dumlupınar Üniversitesi Sosyal Bilimler Dergisi, 29, 245-262.

Schmidbauer, H., Gençer, M., Cilingir, C.B., Tunalıglu, V.S., 2007. Sanal Dünyada Varolmak: Üniversite ve İnternet. Akademik Bilişim Kongresi, Kütahya, https://ab.org.tr/ab07/bildiri/150.pdf.

Sigg, S., Lagerspetz, E., Peltonen, E., Nurmi, P. ve Tarkoma S., 2019. Exploiting Usage to Predict Instantaneous App Popularity: Trend Filters and Retention Rates. ACM Transactions on the Web, 13(2), 1-25.

Storto, C., 2013. Evaluating Ecommerce Websites Cognitive Efficiency: An Integrative Framework based on Data Envelopment Analysis. Applied Ergonomics, 44, 1004-1014.

Şenol, O., Metin, A. ve Korucu, K.S., 2019. Ülkelerin Ölüm Göstergeleriyle Karşılaştırılması: Veri Zarflama Analizi. Süleyman Demirel Üniversitesi Sosyal Bilimler Enstitüsü Dergisi, 2(33), 82-103.

Xing, Y., Li, L., Bi, Z., Wilamowska-Korsak, M. ve Zhang, L., 2013. Operations Research (OR) in Service Industries: A Comprehensive Review. Systems Research and Behavioral Science Syst. Res., 30, 300-353.

Yıldız, N.Ç. ve Güneş, M.Ş., 2017. Örgütsel Stresin, Örgütsel Sessizlik ve Tükenmişlik Üzerine Etkisi: Eczane Çalışanları Üzerinde Bir Araştırma. Uygulamalı Sosyal Bilimler Dergisi, 1(1), 45-66. 